\title{
How to handle import containers safely
}

\author{
Xaver Baur $^{1 *}$, Alf-Magne Horneland ${ }^{2 \#}$, Axel Fischer ${ }^{3}$, Ralf Stahlmann ${ }^{4}$, Lygia Therese Budnik ${ }^{5 *}$ \\ ${ }^{1}$ Institute for Occupational Medicine, Charité University Medicine, Charité-Campus Benjamin Franklin Berlin, Germany \\ ${ }^{2}$ Norwegian Centre for Maritime Medicine, University of Bergen, Bergen, Norway \\ ${ }^{3}$ Charité Campus Virchow Clinic, Department of Infectiology and Pneumonology, Pneumonological Oncology, \\ Division of Clinical Allergology, Charité University Medicine, Berlin, Germany \\ ${ }^{4}$ Institute of Pharmacology and Toxicology, Charité University Medicine, Charité-Campus Benjamin Franklin, Berlin, Germany \\ ${ }^{5}$ Institute for Occupational and Maritime Medicine (ZfAM), University Medical Centre Hamburg-Eppendorf, \\ Division of Occupational Toxicology and Immunology, University of Hamburg, Hamburg, Germany \\ *European Society for Environmental and Occupational Medicine (EOM) \\ \#International Maritime Health Association (IMHA)
}

\section{INTRODUCTION AND REPORT}

Millions of freight containers, which criss-cross the planet and are disinfected by use of pesticides, can represent a real risk to the health. One of the commonest requirements for containers is to be fumigated using toxic gases, which are dangerous to the health not only of dockers, other port staff and transport workers involved in unloading imported production parts and goods, but presumably also to vulnerable end-consumers. The $7^{\text {th }}$ International Workshop "How to handle import containers safely" focusing on health aspects associated with the global transport of goods took place on 22 $2^{\text {nd }}$ and $23^{\text {rd }}$ May 2014 at the Charité Institute of Occupational Medicine in Berlin, Germany. The workshop was organised jointly by the European Society for Environmental and Occupational Medicine (EOM) and the International Maritime Health Association (IMHA) [1]. It was attended by c. 80 international experts and focused on overviews on the current health risks due to volatile toxic substances in transport and unloading various goods, also touching the causative production and shipping processes. The major aims of the workshop were to develop and initiate multidisciplinary based awareness on pesticides and toxic chemicals in global transport and warehousing. Ongoing and pilot studies were introduced. Presentations referred also to assessment of hazardous exposures in the workplace (especially in harbours), the role of biomonitoring and fine diagnostics. It is important to mention that international transport of all kinds of goods (raw materials, parts of/assembled finished products, E-waste) is still increasing [2], and is mostly carried by container ships crossing the oceans with several hundred millions of containers. Container and other transport units are transferred unopened deep into the country-site anywhere in the globalized world. We are all part of a global economy, capable of producing and transporting seemingly anything, from anywhere, to anyone. Its lifeblood is an interconnected network of suppliers and producers, retailers and consumers, spanning the planet [2]. Ports like Hong Kong and huge warehouses feed global supply chains, but their social and environmental costs are largely hidden [2].

\section{WHAT IS THE RISK AND WHO IS AT RISK?}

All fumigants which are used to protect the transported freight from alien species and to inhibit their spread to foreign countries are toxic to humans affect mainly the central and peripheral nervous system and the respiratory tract (Ritz, Baur). But also cancer may occur and other organs such as the liver and the skin may be involved (Stahlmann) (Fig. 1) [3]. Further, recent studies identified a varying spectrum of toxic industrial chemicals released from the newly manufactured transported products, endangering similarly workers in the production line, harbour workers, seafarers, inspectors, employees of logistic companies as well as the usually uninformed workers of importing enterprises unloading the products (Zhao, Bratveit and Djurhuus, Verschoor A.). Between $10 \%$ and $20 \%$ of all important containers were shown to have volatile toxic substances above the exposure limit values (Baur, Budnik, Johanson). A number of intoxications, some with lethal outcome, undermine the relevance of respective exposures (Denisenko, Kong, Jespen, de Jong, Bratveit/Djurhuus).

Ongoing studies focus on the release of these toxic volatile substances from various goods and it was shown that the half-lives range between minutes and months, depending on the toxic substance, its concentration, temperature, the matrix/goods, the density of their packing and chemical

Prof. Dr. Xaver Baur, Institute for Occupational Medicine, Charité University Medicine, Charité-Campus Benjamin Franklin Berlin, Germany; European Society

for Environmental and Occupational Medicine (EOM), e-mail: Xaver.Baur@charite.de 


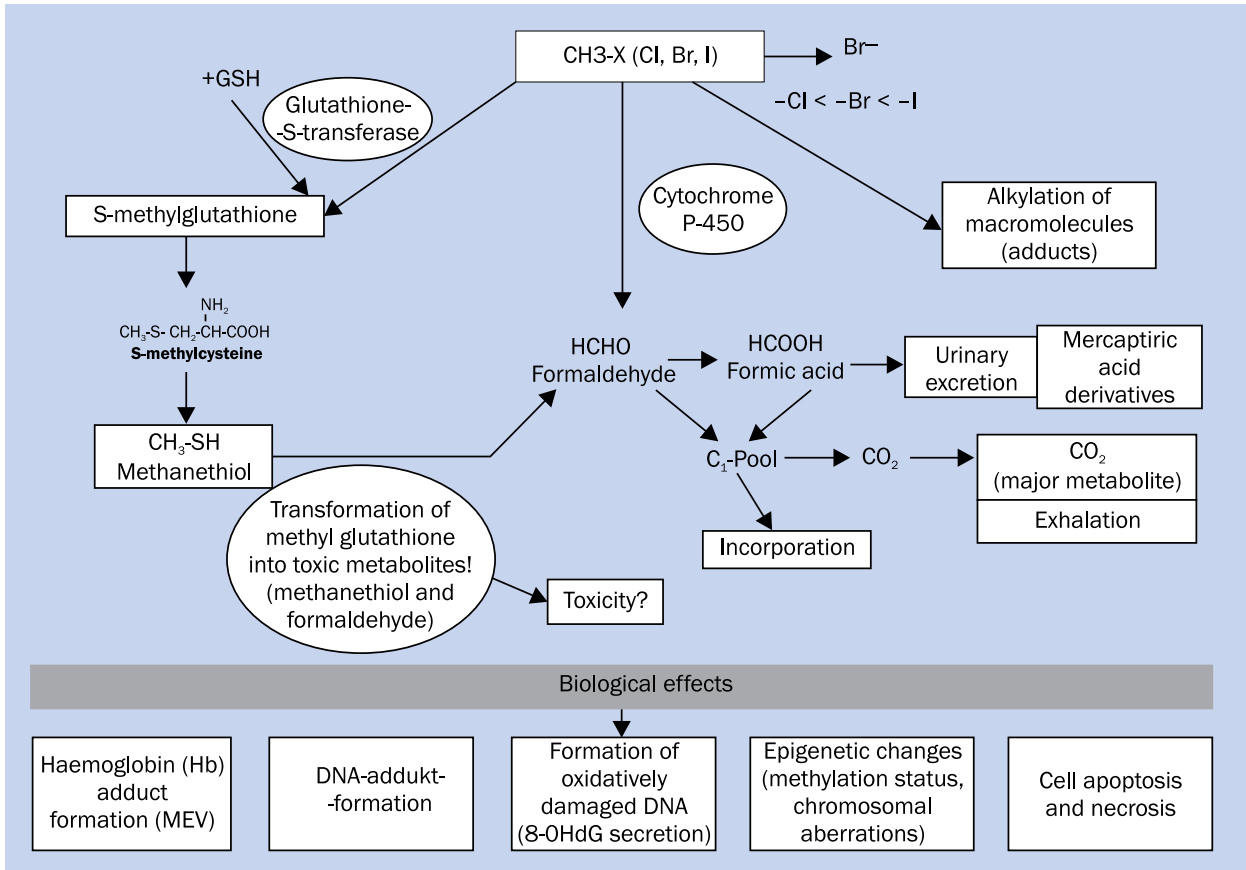

Figure 1. Mechanisms of methyl bromide-induced toxicity modified from Budnik et al. [3]

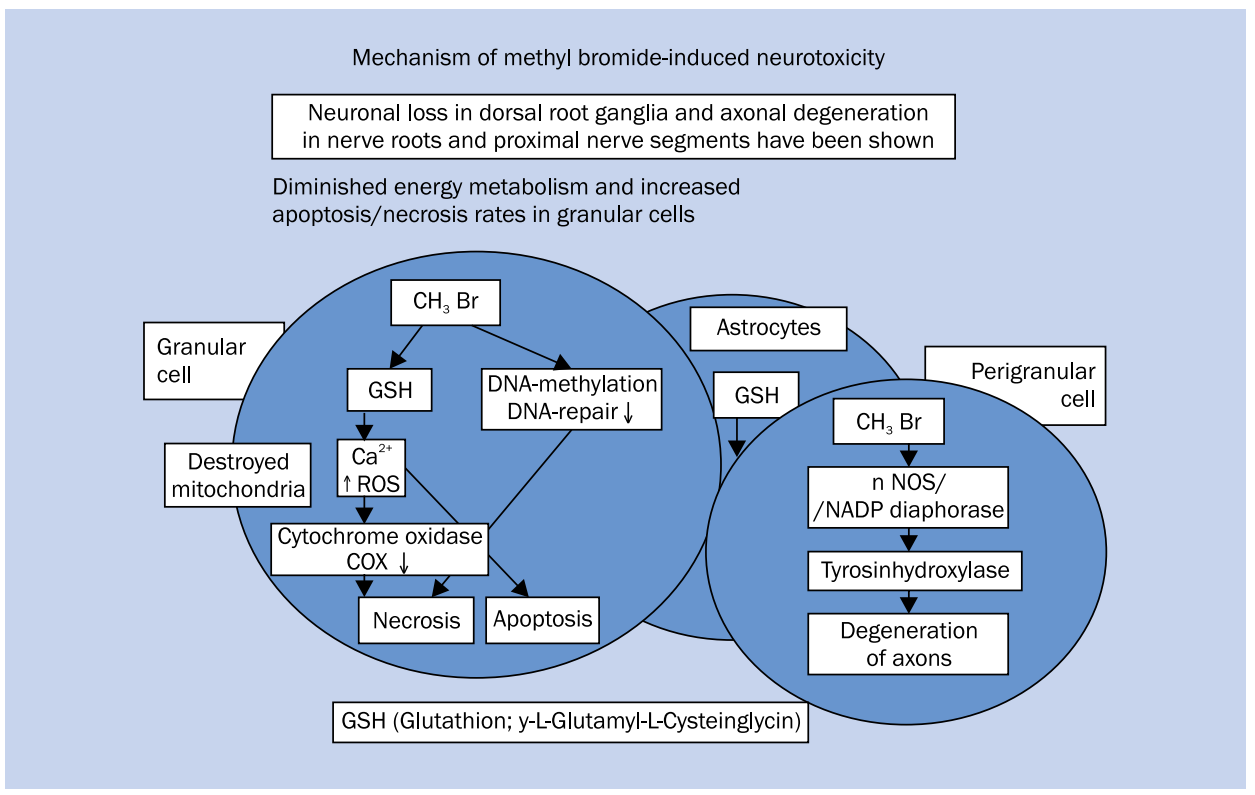

Figure 2. Mechanisms of methyl bromide-induced neurotoxicity modified from Budnik et al. [3]

reactivity (Schubert, Flingelli). Regulations on declaration and handling dangerous goods are mostly not followed (Lucas, Budnik). The risk of the vulnerable consumer is obvious but not studied in detail so far.

\section{OCCUPATIONAL HYGIENE}

As shown by the Hamburg customs effective aeration of container or documented measured absence of toxic airborne substances before entering a container prevents from intoxications (Fig. 2). However, it is important to measure not only directly behind the container door (where concentrations may be low due to leakages), rather, also deep inside the container. A new flat lancet facilitates this procedure (Johanson). Forced ventilation rapidly reduces toxic concentrations in the container atmosphere (Keller, Johanson, Flingelli); 
Table 1. In case of assumed intoxication the most important step is an immediate diagnostic set-up by an experienced physician

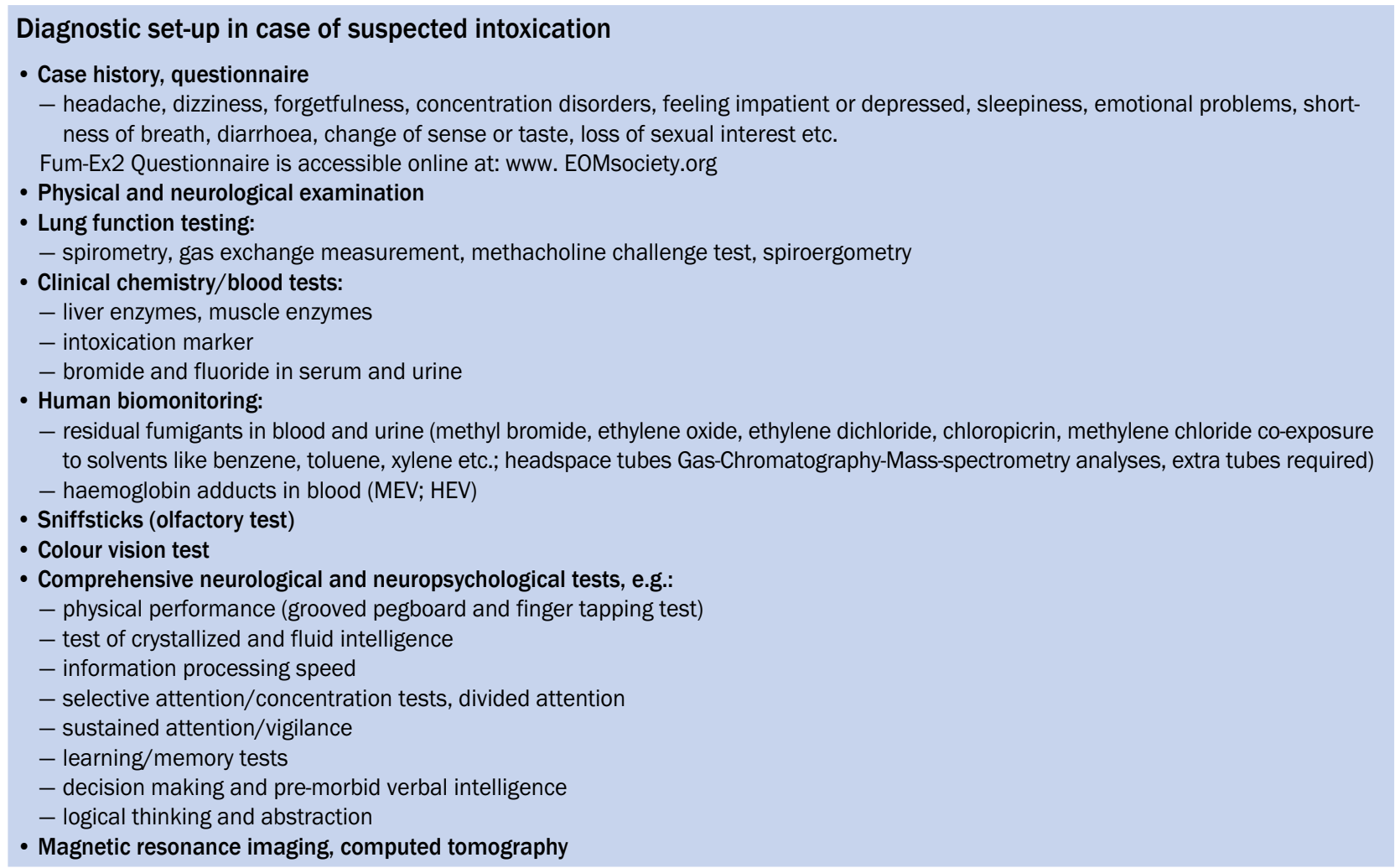

however offgassing within the following hours or days from the goods which may have absorbed toxic substances have to be taken into consideration. It is difficult to measure all possible toxic substances in the container atmosphere; especially formaldehyde and phosphine are not adequately analysed by many devices. So far, no ideal portable non-expensive device is on the market (Budnik, Johanson, Walte).

\section{FINE DIAGNOSTICS}

In case of assumed intoxication the most important step is an immediate diagnostic set-up by an experienced physician. A detailed clinical history and sophisticated occupational history have to be taken (questionnaires already available in different languages may facilitate this) [4]. This is followed by physical examination and functional tests (Table 1) of the obviously affected organs (Baur, Verschoor). Frequently additional medical experts, especially the neurologist and pneumologist have to be consulted and specific diagnostic investigations (e.g. neurological, vision and olfactory function tests, MRT, CT) initiated (Baur). Biomonitoring should be done immediately, as it is helpful to identify causative toxic substances (for necessary procedure see Table 1). Biomonitoring is also recommended for screening of frequently exposed subjects such as employees of fumigation companies (Budnik).

\section{PREVENTION}

It is obvious that the outlined worldwide endangering situation in freight transport urgently necessitates several preventive steps. Manufacturers, exporting and importing companies, harbour and logistic enterprises, but also plants receiving import containers have to be informed in detail on the hazards arising from volatile toxic substances in the container atmospheres. This should also include broad information on already existing regulations such as those from International Labour Organisation (ILO), national authorities (Kosbayeva, Rubino) as well as on useful precautious measures. It is also necessary to have regular controls by the authorities on a worldwide scale, which should be followed by sanctions in case of disregarding regulations. Further, fumigated containers must have a warning sign corresponding to international recommendations and national regulations, and freight documents have to indicate any potential hazard during stripping the goods. No container should be entered if hazardous airborne exposures are not excluded, i.e. only after appropriate measurement of an air sample (taken deep inside the container, likely via a flat lancet, at bottom, middle, top of the container) or aeration, where extraction ventilation were shown to be most effective (which necessitates some redesigning containers, e.g. by a hole in the back for applying the extraction pipe). Ventilation should be ongoing in initially contaminated contain- 


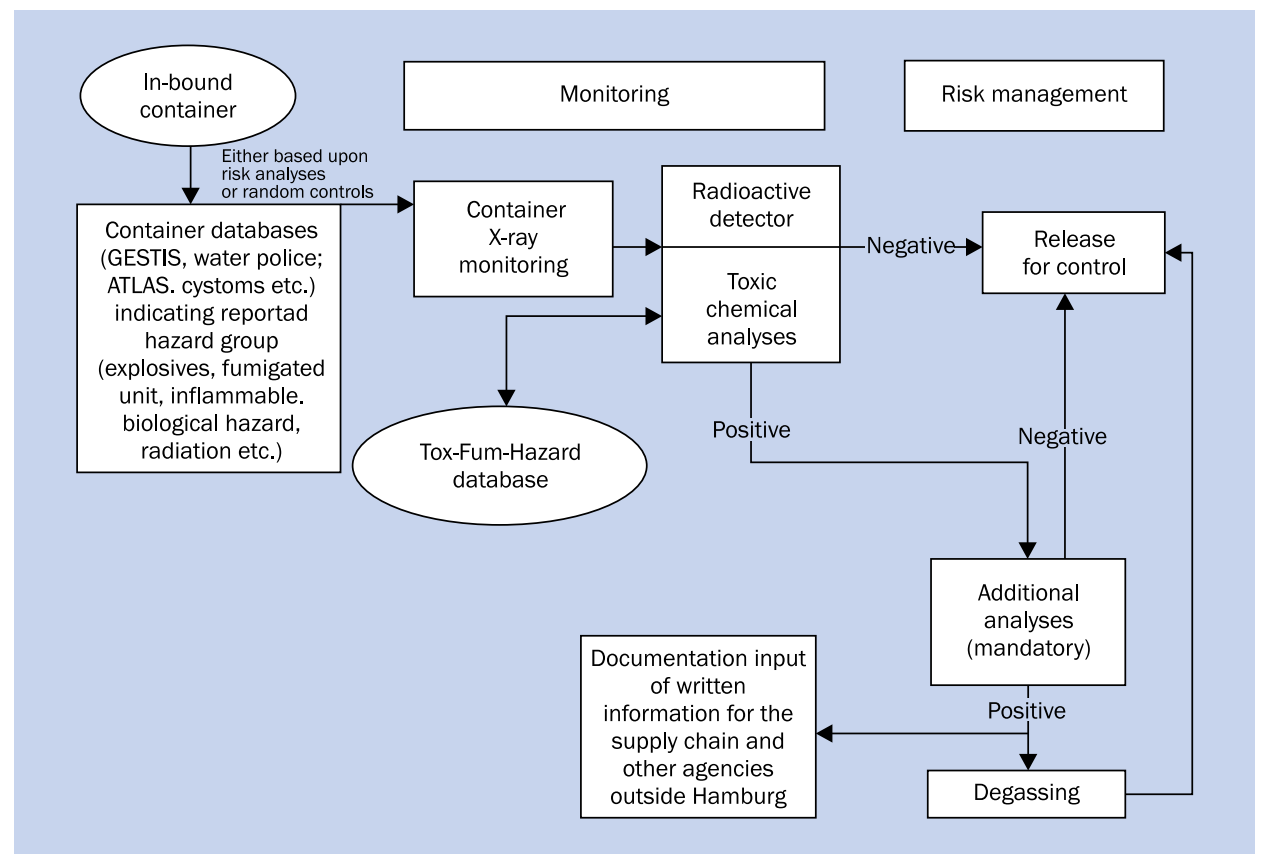

Figure 3. Preventive measures model monitoring system existing within the state of Hamburg (initiated and developed in cooperation with Institute for Occupational and Maritime Medicine [ZfAM] in 2010)

ers during stripping and significant offgassing from goods, frequently for days or even weeks have to be considered (Johanson and Svedberg). More effectively, alternatives for fumigation (such as heat treatment, use of oxygen-depleted air) should be promoted and introduced and toxic industrial chemicals replaced by non-endangering substances. The many still existing knowledge gaps, e.g. possible structural modification of food by fumigants [5], the health risk of the consumers, should be taken into consideration by aimed research projects.

We insist that measuring levels of fumigation gases is not enough, and that monitoring must be extended to all other toxic substances. In the meantime, lessons must be learned from the presented studies, especially since the fumigants are often colourless and odourless, and dangerous even at low concentrations. Further details and results are shown below (abstracts). In order to foster these urgently needed preventive measures, a new working group headed by EOM and IMHA will take action.

\section{CONTAINER MONITORING FOR HAZARDS: HAMBURG CUSTOMS MODEL PRESENTED AT THE WORKSHOP}

The first comprehensive prevention measures system - which can be considered to be a "State of the art model" - has been implemented in the harbour of Hamburg. The existing risk assessment system is a part of the daily routine to protect the controlling bodies from the incidents associated with all kinds of terrorist or criminal threats in the container air and freight. If the screening detection is positive, additional mandatory analytical toxicological measurements in specialised analytical laboratory are required (Fig. 3). The state labour inspection office (Health and Safety Executive Hamburg) in cooperation with the Institute for Occupational and Maritime Medicine (ZfAM) in 2010 developed a catalogue of minimal requirements needed to be fulfilled for such analysis and the evaluation system. It is free to the logistic companies to choose the laboratory as long as they comply with the minimal requirement system established [6]. The transit container receipt has to indicate information about a possible chemical hazard, if present. Unfortunately, due to lack of communication between the European controlling agencies this information cannot be forwarded.

\section{TOXICITY OF FUMIGANTS}

Short introduction - see Figures 1 and 2.

\section{ACKNOWLEDGEMENTS}

The workshop included our WHO-GPA collaborating projects "New chemical health risk hazards in transportation and warehousing of cargo due to the process of globalisation" (LTB)s on Health Hazards through global trade. We thank the Word Heart Organisation for supporting this project.

\section{CONFLICT OF INTERESTS}

All authors declared to have no conflict of interests. 


\section{REFERENCES}

1. www.eomsociety.org/attachments/Agenda_InternationalWorkshop222305\%20142004(2).pdf.

2. Science Special Issue: "Rethinking the Global Supply Chain". 2014; 6 June: Vol. 344, no. 6188.

3. Budnik LT, Kloth S, Velasco-Garrido M, Baur X. Prostate cancer and toxicity from critical use exemptions of methyl bromide: environmental protection helps protect against human health risks. Environ Health 2012; 11: 5-18.

4. Fum-Ex2 Questionnaire: http://www.eomsociety.org/attachments/ FUMEX2_QUESTIONNAIRE_EOM_ENGLISH\%2OVERSION.pdf.

5. Food and Agriculture Organization of the United Nations. International standards for phytosanitary measures. Guidelines for Regulatory Wood Packing Material In International Trade. ISPM Pub, ISPM No. 15. N 6, Rome 2007.

6. Boels D, Krutisch I, Fahrenholtz S, Baur X, Budnik LT. [Anforderungen an die Messung und Begutachtung der Schadstoffbelastung in der Luft von Importcontainern]. Zbl Arbeitsmed 2010; 60: 130-136.

\section{SUMMARY OF SELECTED ORAL PRESENTATIONS}

\section{HOW TO DETECT AND DIAGNOSE INTOXICATIONS? PROBLEMS AND CHALLENGES}

\section{Xaver Baur}

European Society for Environmental and Occupational Medicine (EOM)/Institute of Occupational Medicine, Charité University Clinic Berlin, Germany

Prof. Dr. Xaver Baur — e-mail: Xaver.Baur@Charite.de

Background: Acute or chronic intoxications by fumigants or toxic industrial chemicals are typically associated with non-specific symptoms and therefore frequently misdiagnosed. The consequence may be ongoing hazardous exposures in the workplace with deleterious, frequently non-reversible, disorders. This necessitates awareness of respective endangering exposures in the workplace by the worker and the physician.

Methods: In detail examined intoxicated cases from our outpatient department as well as from the literature were taken into consideration with special regard of proven exposures, exposure-related symptoms and pathological findings. Furthermore, a questionnaire was developed on basis of this data.

Results and conclusions: The crucial initial step is the detailed occupational and clinical history taken by an experienced physician who is aware of the possible causative exposure to volatile toxic substances in the workplace. One known detailed very detailed questionnaire is available from Safe Work Australia [1]. Based on the literature as well as on our own clinical experience we have developed a new comprehensive questionnaire (FumEx), now available in three languages [2]. It was shown in several application sites to be very useful in field studies and individual intoxication cases, not to be too time-consuming and to be easy to handle by the patient by adding information by the physician performing the always needed personal interview. FumEx allows to settle/fix time, duration and kind of workplace exposures [3], applied protective devices, and detect acute and chronic symptoms related to exposures or independent from the workplace. For the full diagnosis the job history is followed by physical examination and functional tests of probably affected organs such as lung function testing, blood analyses, neurological and neuropsychological investigations $[4,5]$. Abnormal findings may necessitate sophisticated examinations by other medical disciplines such as the neurologist or pneumologist; also MRT or cranial CT may be indicated. Early starting of biomonitoring helps to identify the causative toxic substance. Unfortunately, there is no specific therapy and no antidote is available; only symptomatic treatment is possible.

\section{References}

1. Safe Work Australia: Hazard Surveillance: Residual Chemicals in Shipping Containers: http://www.safeworkaustralia.gov.au/sites/ swa/about/publications/pages/hazard-surveillance-residual-chemicals-in-shipping-containers. December 2012.

2. Fum-Ex2: Fumigant Exposure Questionnaire http://eomsociety. org/attachments/FUM-EX\%202_\%20QUESTIONNAIRE_EOM\%20 ENGLISH\%2OVERSION.pdf.

3. Budnik LT, Kloth S, Baur X, Preisser AM, Schwarzenbach H. Circulating Mitochondrial DNA as Biomarker Linking Environmental Chemical Exposure to Early Preclinical Lesions: Elevation of mtDNA in Human Serum after Exposure to Carcinogenic Halo-Alkane-Based Pesticides. PloS One 2013; 8: e64413, doi:10.1371/journal. pone.0064413.

4. Preisser AM, Budnik LT, Baur X. Health effects due to fumigated freight containers and goods: how to detect, how to act. Int Marit Health 2012; 63: 133-139.

5. Preisser AM, Budnik LT, Hampel E, Baur X. Surprises perilous: toxic health hazards for employees unloading fumigated shipping containers. Sci Total Environ 2011; 409: 3106-3113.

\section{RESEARCH BASED INFORMATION TO INVOLVED BODIES ON HEALTH RISKS DURING UNLOADING OF TRANSPORT UNITS; KEY INFORMATION EXTRACTED FROM FUMIGATION INCIDENCES AND FROM EXISTING RESEARCH ON FUMIGANTS, VOCS AND OTHER HAZARDOUS MATERIALS}

\section{Magne Bråtveit ${ }^{1,2}$, Rune Djurhuus ${ }^{3}$, Bjørg Eli Hollund ${ }^{1}$, Jorunn Kirkeleit ${ }^{1}$, Arne Johan Ulven ${ }^{3}$, Tor B. Aasen ${ }^{1}$}

${ }^{1}$ Department of Occupational Medicine, Haukeland University Hospital, Bergen, Norway

${ }^{2}$ Occupational and Environmental Medicine, University of Bergen, Bergen, Norway

${ }^{3}$ Norwegian Centre for Maritime Medicine, Haukeland University Hospital, Bergen, Norway

Prof. Dr. Magne Bråtveit — e-mail: Magne.Bratveit@igs.uib.no 
Background: There has been very little focus on potential health risks associated with unloading of fumigated transport units in Norway. This presentation aims to describe extraction of present knowledge on this topic in order to disseminate research based information to involved bodies such as employers and employees organisations, authorities and occupational health personnel.

Methods: A multidisciplinary team comprising physicians, occupational hygienists and toxicologists was established. Information about present status on container handling was gathered through workplace visits and interviews with employers and workers at Bergen harbour and at selected distributors. Literature search was done in PubMed and supplemented by Google-search for relevant reports containing information about measurements of pesticides or VOC's in sets of containers. Totally seven articles and reports from the Netherlands, Germany, Sweden, Australia and BeNeLux were selected for this study.

Results: The majority of containers with residual pesticides seemed to come from Asia and America. There seemed to be no consistent distribution of pesticides between types of cargo except for phosphine in foodstuffs. Formaldehyde was most frequently detected, with methyl bromide and phosphine next, all detected in 6 of 7 studies, while chloropicrin was detected in 4 of 7 studies. A considerable number of containers had residual pesticide concentration that exceeded occupational exposure limits. In worst case scenarios the maximum concentration detected of both methyl bromide and phosphine could result in fatal outcomes of exposed personnel. No reports documenting accidents with fatal outcome were found from exposure by opening/unloading of freight containers; however, several documented examples of fatalities from fumigated bulk cargo ships were found. Possible actions to mitigate the risk of injuries by pesticides from freight containers include mandatory labelling, ventilation before opening and use of PPE.

Conclusions: The risk of acute health effects is related to potentially high exposures to pesticides during unloading of fumigated containers, while voCs from goods presumably have lower acute toxicity. Except for phosphine in foodstuffs, there seems to be no consistent distribution of pesticides between types of cargo. Thus, information to involved bodies might not be specifically linked to countries of origin, fumigation agents or type of cargo, but should rather include general descriptions and information on precautionary measures such as reasons for fumigation, missing labelling procedures, fumigation agents, potential health effects and relevant control measures.

\section{FUMIGATION OF EXPORTED CONTAINERS AND OCCUPATIONAL HEALTH OF WORKERS: A PILOT STUDY IN CHINA}

\section{Zhiwei Zhao}

Centre of Maritime Health and Society, University of Southern Denmark, Dalian Maritime University, China

Dr. Zhiwei Zhao _ e-mail: zhaozhiwei2006@hotmail.com

With more than 30 years economic reform, Chinese government is now paying more attention to the working condition and health and safety issues of workers than ever before. There are researches in China considering the occupational health of the workers of different industries, e.g. construction workers, nurses and firemen, etc. Although a number of researches have been carried out in western societies, nevertheless very little attention has been paid to the working process or the occupational health of workers in the field of container fumigation in China.

This is a pilot study of a potential international-cooperative research project. It discusses initially who is operating the business of fumigation in China and how work has been organised. It also considers the working condition and health issues of workers and their perceptions regarding their jobs. The research draws on a case study of a Chinese stateowned company fumigating exported containers. Qualitative methods are utilised, with 2 managers being interviewed extensively and 4 workers being group interviewed under the 'supervision' of the managers. The presence of the managers may prevent workers from expressing their true concerns and thus weakens the analysis to some extent. However, available data still provide some meaningful explanations as to what is happening in that particular field.

The case study shows that within the province, the business of fumigating exported containers is monopolised by the researched state-owned company. It provides training to its workers and issues them professional certificates. This state-owned company obtains credentials of operating fumigation and issues official certificates to the fumigated containers, which are highly recognised by foreign consignees. None of these could be done by any other companies in the province. Such monopolisation may have some positive implications to the working condition of workers. It is observed from the work site that workers wear working suits, masks, gloves. They think the job is simple and safe. They do not report any symptoms or diseases that might be related to chemical exposure. They seem very content with their jobs.

It is possible that workers did not thoroughly express their concerns about their working condition and occupa- 
tional health because of the presence of their managers. Workers are in a very weak position. Most of them are peasant workers, who are temporarily employed, offered low wages, are not provided with any social insurances and have little job security. They are specifically trained for fumigation jobs and hence they depend on their managers for work opportunities. The protection and support to these migrant workers is an important issue that needs addressing.

It is also seen that since European countries started to inspect the level of toxic chemicals in the imported containers more strictly than before, the company in the case study stops fumigating the containers exported to European countries by using toxic chemicals. Instead, heat treatment is applied. This might imply that a stricter regulation helps with the reducing of using toxic chemicals.

Funding: no funding

Conflict of interest declaration: none

\section{REGULATIONS OF AND AUTHORISATION FOR APPLICATION OF FUMIGANTS}

\section{Federico Maria Rubino, Claudio Colosio}

Department of Health Sciences of the University of Milano and International Centre of Rural Health, San Paolo University Hospital Milano, Italy;

$\mathrm{CC}$ is WHO Global Plan of Action priority leader for the agricultural sector

Prof. Dr. Claudio Colosio - e-mail: claudio.colosio@unimi.it

Fumigation is the treatment aimed at controlling pests and other undesired organisms in items and closed spaces through the exposition to toxic atmospheres obtained by dispersing or generating poisonous chemical compounds in the enclosures. In trans-continental trade, this procedure is aimed at avoiding the transfer of micro-organisms, plants, insects and animals to foreign countries as hosts of commercial loads, such as shipped or air-transported bulk products and freight containers, and to avoid spoilage of perishable goods and of food. Fumigation is obligatory under international regulations and follows internationally agreed procedures to ensure efficacy, to avoid deterioration of the treated goods and to avoid harm to workers in all phases of the process.

Only a few chemical products are authorised for this use and alternative procedures, not entailing the use of toxic chemicals, are currently experimented. Of the three chemicals authorised for fumigation, one, bromomethane, is an ozone depletory and finds only residual use subject to specific authorisation in limited amounts. The most widely used fumigant is phosphine, which is most commonly released from aluminium and magnesium phosphides under the action of ambient and product humidity. Sul- phuryl fluoride is gaining an increasing use due to its more favourable properties (not flammable and less hazardous for the operators).

Especially methyl bromide and phosphine are the cause of serious occupational accidents due to overexposure. Methyl bromide is a neurotoxic substance and the literature reports more than 300 cases of intoxication, often with fatal consequences or with permanent disability. Phosphine is a lung and blood toxic and, due to its use in in transit fumigation, exposure of seamen can occur during not only operations but also off-duty, often in unexpected and increasingly dangerous circumstances, such as in accommodation blocks.

The application techniques aim at ensuring treatment of the goods, especially of bulk products in ships holds, with a sufficient concentration of the fumigant, considering the transport time and the necessity to avoid dangerous exposure of workers during fumigation, transport and inspection/ /unloading. Airtight closure of the holds and segregation of fumigated containers on board is necessary to avoid exposure of sea workers during transport. The measure of actual concentration of fumigants is possible from long time with simple and reliable devices that have been improved by use of modern technology. Availability and correct use of appropriate protection by trained workers in all critical phases of work is obligatory and necessary. Accurate labelling of freight containers with the indication of actual treatment that is carried and log keeping of their past use is obligatory and greatly helps to provide information to avoid accidents and acute intoxication.

\section{HEALTH HAZARDS: WHO POINT OF VIEW UNDER THE INTERNATIONAL FRAMEWORK}

\section{Aliya Kosbayeva, Elizabet Paunovic}

WHO European Centre for Environment and Health

Dr. Aliya Kosbayeva — e-mail: kosbayevaa@ecehbonn.euro.who.int

WHO Global Burden of Disease Report proved that poor working environment is among the top ten health risk factors. In the WHO European Region alone with over 400 million workers, $5 \%$ of GDP are lost every year due to work-related diseases and accidents. Unhealthy working conditions contribute to $1.6 \%$ of the burden of disease. Globally, about $70 \%$ of workers are not insured to compensate them occupational diseases and injuries.

Global growth of non-communicable diseases, and particularly, cardiovascular and diabetes in the WHO European Region are of a great concern.

Considering preventable nature of all occupational diseases, the improvement of working conditions and work 
organisation can significantly reduce the burden above-mentioned conditions.

To address risks of public health concern generally and in relation to chemical incidence and environment, WHO has spectrum of documents and guidelines. Thus, International Health Regulations (IHR), international legal instrument that is binding on 196 countries across the globe. Their aim is to prevent and respond to acute public health risks that have the potential to cross borders and threaten people worldwide. Within the framework of IHR, handbook for inspection of ships and issuance of ship sanitation certificates became available.

Universal health coverage, global WHO initiative, addressing health determinants (health promotion and prevention of risk factors for non-communicable diseases) with the financial protection that prevents ill health leading to poverty is one general approach.

Workers' Health Global Plan of Action, aiming at national policy improvement via specific health programmes, improved surveillance and occupational services coverage, inspection and enforcement activities put emphasis on the primary prevention of occupational diseases and injuries by introducing healthy work practices and work organisation, and of a health-promoting culture at the workplace.

\section{REGULATION AND PRACTICE OF WORKERS' PROTECTION FROM CHEMICAL EXPOSURES DURING CONTAINER HANDLING}

\section{Balázs Ádám ${ }^{1,2}$, Randi Nørgaard Fløe Pedersen ${ }^{1}$, Jørgen Riis Jepsen ${ }^{\mathbf{1}}$}

${ }^{1}$ Centre of Maritime Health and Society, Institute of Public Health, University of Southern Denmark, Denmark

${ }^{2}$ Institute of Public Health, College of Medicine and Health

Sciences, United Arab Emirates University, United Arab Emirates

Ass. Prof. Dr. Jørgen Riis Jepsen — e-mail: jriis@sdu.dk

Introduction/Background: Fumigation of freight containers to prevent spread of pests and offgassing of freight are sources of volatile chemicals that may constitute significant health risks when released. The aim of our study is to investigate the regulation and practice of container handling in Denmark with focus on preventive measures applied against chemical exposures.

Methods: A comprehensive systematic search of scientific literature, legislation and recommendations related to safe work with transport containers from international and Danish regulatory bodies was performed. The practice of container work was investigated in a series of semi-structured interviews with key informants including managers and safety representatives of organisations that handle containers.
Results: Although several international and national regulations and local safety instructions relate to container handling, the provided information is not sufficiently detailed to conduct safe practice in many aspects. In accordance with the scientific literature, the interviewees estimate that there is a high frequency of containers with hazardous chemical exposure that are regarded as potentially damaging to health, although recognisable health effects are rare. There is limited knowledge about the types of chemicals, which mostly cannot be measured by available devices at the worksite. Passive ventilation and personal protective equipment are typical preventive measures in practice, but their use is not consistent and does not necessarily ensure adequate protection.

Conclusions: Hazardous chemical exposure from containers does constitute a risk, about which, however, managers, workers, even occupational health professionals have limited knowledge. Detailed risk assessment and specific instructions on risk management are needed for safe handling of transport containers.

\section{OFFGASSING FROM FUMIGATED GOODS AND PRODUCTS: ONGOING RESEARCH PROJECT FOR FUTURE DETAILED HEALTH RISK ANALYSIS}

\section{Jens Schubert ${ }^{1}$, Svea Fahrenholtz ${ }^{2}$, Harald Jungnickel ${ }^{1}$, Dagmar Klementz ${ }^{3}$, Lygia Therese Budnik ${ }^{2}$, Andreas Luch ${ }^{1}$}

${ }^{1}$ German Federal Institute for Risk Assessment (BfR), Department of Product Safety, Berlin, Germany

${ }^{2}$ Institute for Occupational and Maritime Medicine (ZfAM), University Medical Centre Hamburg-Eppendorf, Division Occupational Toxicology and Immunology, Hamburg, Germany ${ }^{3} J u l i u s$ Kühn-Institut (JKI), German Federal Research Centre for Cultivated Plants, Institute for Ecological Chemistry, Plant Analysis and Stored Product Protection, Berlin, Germany

Dr. Jens Schubert - e-mail: Jens.Schubert@bfr.bund.de

Background: Fumigation of transport containers is a common practice to protect consumer goods from pests in the shipping industry or to avoid the spread of alien species (ISPM 15 Directive, Food and Agriculture Organisation). However, little is known on the effects caused by these substances on the fumigated goods and the related health risks.

Methods: Several matrices (e.g. sunflower seeds, soaps, apples, et al.) were analysed with respect to their adsorption and desorption behaviour of selected fumigants (methyl bromide, phosphine, 1,2-dichloroethane). Fumigation and subsequent desorption were performed on a laboratory scale using fumigation chambers or desiccators. The fumigants used were quantified by either TD-2D-GC-MS/FPD or GC-MS instrumentation. Furthermore, the impact of the fumigation concentration and the desorption temperature 
were assessed. Finally, a surface analysis of the fumigated matrices was performed using ToF-SIMS instrumentation to identify possible fumigation residues.

Results: The desorption of fumigants depends mainly on the treated matrix. For some matrices (e.g. sunflower seeds, soaps) it was revealed that the desorption lasts over a long period and that considerable amounts of the used fumigants are released. This may result in concentrations way above occupational exposure limits, if the fumigated goods are stored in enclosed spaces.

Conclusions: Considering the obtained results, fumigated consumer goods can pose a health risk to workers and consumers. However, further research is urgently required.

Funding: this work was supported by the German Federal Institute for Risk Assessment (BfR)

Conflict of interest: the authors declare that they have no conflict of interest

\section{IDENTIFYING CHEMICAL AGENTS THAT CAUSE NEURODEGENERATION IN HUMANS: INSIGHTS GAINED FROM STUDYING GENE-ENVIRONMENT INTERACTIONS IN PARKINSON'S DISEASE}

\section{Beate Ritz, Pei Chen Lee, Shannon Rhodes, Arthur Fitzmaurice, Myles Cockburn, Janet Sinsheimer, Jeff Bronstein}

University of California Los Angeles, United States, University of Southern California, United States

Prof. Dr. Beate Ritz — e-mail: britz@ucla.edu

Introduction/Background: Epidemiologic, animal and cell based studies suggest that pesticide exposures increase the risk of developing Parkinson's disease (PD). Most previous human studies relied on recall of chemicals exposures and did not point out specific agents or mechanisms for the action of a toxin. Experimental models on the other hand are 'better or worse' attempts of modelling a human disease. Human genetic variations that increase vulnerability to the neurotoxic effects of environmental agents can help us identify vulnerable populations and biologic mechanisms of neurodegeneration that eventually can also be targeted by therapeutics.

Methods: In conducted a large case controls study conducted in Central California to examine how longterm human pesticide exposure contributes to PD. We used a unique geographic information system based pesticide exposure assessment tool that incorporates land use maps and agricultural pesticide application records for California. We assessed neurodegeneration and cognitive decline due to the action of specific pesticides as well as interactions between pesticides and genetic factors that increase susceptibility or resilience to these environmental toxins. We selected genes involved in pathogenetic pathways relevant for PD or in pesticide detoxification.

Results: We estimated increased risk for PD with exposures to combinations of paraquat and maneb or ziram, organophosphate and dithiocarbamate pesticides. We also showed that risks were much greater in individuals who carried genetic variants of the dopamine transporter (DAT), paraoxonase 1 (PON1), aldehydedehydrogenase (ALDH2) genes when exposed to pesticides that interact with these genes in biologic pathways. We also found evidence for faster cognitive decline in PD patients exposed to organophosphate pesticides.

Discussion and Conclusions: With our approach we were able to identify important mechanism through which environmental toxicants contribute to PD pathogenesis, especially in genetically vulnerable individuals. It allowed us to identify pesticides likely involved in neurodegeneration in populations with long-term low dose exposures.

Funding: this work was funded in part by the National Institute of Environmental Health Sciences (grants P01ES016732, R01ES010544, 5R21ES16446-2, U54ES012078, T32ES015457), the National Institute of Neurologic Disorders and Stroke (grant NS038367), the Veterans Administration Healthcare System (SW PADRECC), the Michael J. Fox Foundation, the Levine Foundation, and the Parkinson Alliance

Conflict of interest declaration: none

\section{FROM SYMPTOMS OF INTOXICATION TO IDENTIFICATION OF THE NOXIOUS AGENTS: CHALLENGES IN AMBIENT AND BIOMONITORING ANALYSES}

\section{Lygia Therese Budnik}

Institute for Occupational and Maritime Medicine (ZfAM), University Medical Centre Hamburg-Eppendorf, Division of Occupational Toxicology and Immunology, University of Hamburg, Hamburg, Germany; LTB is WHO Global Plan of Action priority Leader for the transport sector

Prof. Dr. Lygia Therese Budnik — e-mail: L.Budnik@uke.de

Introduction: The export of manufacturing production resulted in substantial increase in international trade. Increasing number of containers tainted with industrial chemicals like fumigants (i.e. methyl bromide [1] or other halo-alkanes) may endanger staff of controlling agencies, inspectorates, police, customs, docks and warehouses.

Methods: 4,000 container air samples were analysed (2007-2012) for the presence of fumigants and toxic industrial chemicals [2]. We recruited 164 subjects with presumed intoxication by fumigants (plus 30 controls). 
The exposure assessment was performed with human biomonitoring (screening for methyl bromide, ethylene dichloride, dichloromethane, other halo-alkanes), a standardized questionnaire and comprehensive expert clinical investigation [3].

Results: Ambient monitoring: Our investigations performed in harbours of Hamburg and Rotterdam [2], showed that additionally to the declared hazardous cargoes, more than $20 \%$ of the containers are contaminated with various industrial chemicals without any declaration of a "dangerous" content. Human biomonitoring analyses revealed exposures to halo-alkanes above the non-cancer reference doses (RfD), but (mostly) lower than the occupational exposure limits. 86 individuals with confirmed exposure (out of 164 workers with presumed exposures) to halo-alkane pesticides, we grouped further according to the presence of biomarkers of exposure. Exposure was associated with elevated serum levels of circulating mitochondrial DNA [4] increasing significantly with the time post exposure [4].

Conclusions: In an emergency, appropriate protection measures can be undertaken only if the type of chemical that has been released is known precisely. Personal air samples should be taken along the supply chain, e.g. when unloading import containers and human biomonitoring should be performed for endangered groups.

Funding: this work was funded by the German Ministry of Education and Research, BMBF (Projects DEGENA, Optima) and by research grants from the Erich and Gertrud Roggenbuck Foundation, Hamburg, Germany, and the Hamburg Foundation for Fight against Cancer. The study is also a part of the WHO-GPA collaborating project: "New chemical health risk in transportation and warehousing of cargo due to the process of globalisation"

Conflict of interest declaration: none

\section{References}

1. Budnik LT, Kloth S, Velasco-Garrido M, Baur X. Prostate cancer and toxicity from critical use exemptions of methyl bromide: environmental protection helps protect against human health risks. Environ Health 2012; 11: 5-18.

2. Budnik LT, Fahrenholtz S, Kloth S, Baur X. Halogenated hydrocarbon pesticides and other volatile organic contaminants provide analytical challenges in global trading. J Environ Monit 2010; 12: 936-942.

3. Preisser AM, Budnik LT, Hampel E, Baur X. Surprises perilous: toxic health hazards for employees unloading fumigated shipping containers. Sci Total Environ 2011; 409: 3106-3113.

4. Budnik LT, Kloth S, Baur X, Preisser AM, Schwarzenbach H. Circulating mitochondrial DNA as biomarker linking environmental chemical exposure to early preclinical lesions, PLoS One 2013: http://www. ncbi.nlm.nih.gov/pubmed/23741329.

\section{INTOXICATION WITH METHYL BROMIDE DURING UNLOADING CONTAINERS}

\section{Louis Verschoor, Atie H. Verschoor}

Expertise Centre Environmental Medicine (ECEMed), Rijnstate Teaching Hospital, AA Velp, the Netherlands

Dr. Louis Verschoor and Dr. Atie H. Verschoor - e-mail: I.verschoor@environmentalmedicine.nl

Since 1938 methyl bromide has been used widespread as a fumigant in agriculture. The last twenty years a rapid rise in the use of methyl bromide for fumigation in sea containers is observed. The Treaty of Montreal ended the use of methyl bromide in agriculture to prevent further reduction of the ozone layer caused among others by carbon bromides and - chlorides. Due to its toxicity, the use of methyl bromide in the European Union is forbidden since 2010 , but exceptions are made. The use of methyl bromide to fumigant stow wood in sea containers is allowed until 2015. The rapid rise as a fumigant in sea container transport leads to exposure of methyl bromide in a new group of workers, those handling import containers.

The clinical spectrum of chronic and acute intoxication with methyl bromide will be presented on the basis of three case histories. Two men unloading import containers suffered from chronic exposition to methyl bromide and only came to medical attention after a severe acute intoxication with loss of consciousness. The third patient, a female truck driver, suffered from an acute intoxication after opening the doors of an imported container. She exhibited decreased consciousness, slurred speech and was transported to the hospital.

Acute intoxication is characterised by a first stage of headache, vomiting, sore throat, vertigo and visual disturbance, followed by decreased consciousness to coma and convulsions. Chronic effects can last for years and are confined mainly to the central and peripheral nervous system together with general complaints of fatigue.

In the first two cases it was known that methyl bromide was used as a fumigant, but insufficient safety measures were in place. In the third case no signs of fumigation were present on the outside of the container or on the freight letter. The working conditions under which the exposure took place will be discussed. Since there is no ban yet on the use of methyl bromide the mandatory, precautionary measures to be taken in order to work as safe as possible are reviewed.

Although the follow up in the presented cases range from 1 to 7 years all three people still exhibit chronic health effects and remain unable to work. 
On the basis of all the data available on the health hazards caused by methyl bromide and the cases presented the use of methyl bromide as a fumigant in sea containers should be abolished immediately. Especially since the alternative: Heating of stow wood, is a far better option.

Funding: none

Conflict of interest declaration: none

\section{UNLOADING OF SEA CONTAINERS WITH THESE ITEMS RESULTED IN INTOXICATION OF TWO EMPLOYEES AT THE LOGISTIC COMPANY IN THE NETHERLANDS}

\section{Atie H. Verschoor, Henk J. van Leeuwen, Louis Verschoor}

Expertise Centre Environmental Medicine (ECEMed); Rijnstate Teaching Hospital (internal postbox 2925), AA Velp, the Netherlands

Atie H. Verschoor, PhD - e-mail: a.h.verschoor@environmentalmedicine.nl

A large, electronic company with plants all over Asia encountered health problems caused by exposure to toxic chemicals during the production process at a plant in South Korea. The production includes among others household goods like washing machines, microwave ovens, refrigerators and vacuum cleaners and also mobile phones, tablets and televisions. The products are shipped in containers all over the world. In the Netherlands a large logistic company is responsible for import and distribution of these products.

All products packed in cardboard boxes are transported in containers. Three separate incidents happened during unloading containers with these products within a ten months period (2010). In several containers the card boxes on top and at the back of the container were wet, probably caused by condensation of solvents.

In total five employees were involved in the incidents. All developed acute symptoms during unloading: dizziness, nausea, irritated eyes and throat. Some had difficulty in breathing. One developed also chest pain and loss of muscle tonus. The acute symptoms disappeared after several days. Disturbances in neuro-cognitive function persisted for months. One patient developed cardiographic abnormalities, while all showed liver function disturbances which lasted for weeks. The patient with loss of muscle tonus depicted elevated muscle enzymes for more than a month.

In the first incident the container was not measured for gasses before unloading. The containers of the other incidents were measured by unskilled employees. The second container was declared free of gas. The third container, analysed after ventilation for two hours, showed VOS
39 ppm, styrene $10 \mathrm{ppm}$, toluene $2 \mathrm{ppm}$. The method used is unable to detect 1,2 dichloroethane.

This presentation illustrates that exposure to toxic chemicals occurs during the whole chain from production to delivery. An integrated approach to abolish exposure to toxic chemicals is needed.

\section{FUMIGANTS INTOXICATIONS IN FRANCE: A PILOT DATA}

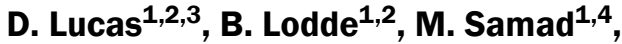 T. Sauvage ${ }^{1,5}$, J.D. Dewitte ${ }^{1,2}$, D. Jegaden ${ }^{1,2,3}$}

${ }^{1}$ French Society of Maritime Medicine, Brest, France

${ }^{2}$ University of Western Brittany, Brest, France

${ }^{3}$ Iroise Occupational Health Institute, Brest, France

${ }^{4}$ CMA CGM Company, Marseille, France

${ }^{5}$ French Seafarer's Health Service, Paris, France

Dr. David Lucas — e-mail: D.LUCAS@metrabrest.com

Introduction: To prepare this presentation, we asked our colleagues in port of Brest, Le Havre, French Seafarer's Health Service and CMA CGM company about fumigants intoxications cases. No cases have been yet reported. Good prevention, lack of knowledge?

Methods: Compilation of French publications on the subject, prevention modalities in port, maritime companies.

Results: We found mostly very recent national publications and prevention process.

Discussion: Communication on fumigation occupational risk and means of prevention need to be developed through university courses, national occupational health journals, website. We also decided to make a study using the EOM questionnaire.

Founding: this work was funded by the French Society of Maritime Medicine

Conflict of interest declaration: none

\section{VENTILATION STUDY FOR IMPORTED CONTAINERS}

\section{François-Xavier Keller}

INRS - Institut National de Recherche et Sécurité; French National Research Institute for Occupational Health and Safety

Dr. François-Xavier Keller — e-mail: francois-xavier.keller@inrs.fr

This study focuses on prevention of possible exposure to chemical agents, when opening, entering and stripping freight containers. The container degassing process is investigated using tracer gas measurements and numerical airflow simulations. Three different container ventilation conditions are studied, namely natural, mixed mode and forced ventilation. The tests conducted allow degassing time 
variations to be quantified in relation to various factors such as container size, degree of filling or type of load. Natural ventilation performance characteristics prove to be highly variable, depending on environmental conditions. Use of a mechanically supplied or extracted airflow under mixed mode and forced ventilation conditions enables degassing to be significantly accelerated. Under mixed mode ventilation, extracting air from the end of the container furthest from the door ensures quicker degassing than supplying fresh air to this area. Under forced ventilation, degassing rate is proportional to the applied ventilation flow. Moreover, degassing rate depends mainly on the location at which air is introduced: the most favourable position being above the container loading level. Many of the results obtained during this study can be generalised to other cases of cleaning air in a confined space by general ventilation, e.g. the priority to be given to positioning air inlets or the advantage of generating high air velocities to ensure maximum stirring of the volume.

Founding: National Fund for the Prevention of Occupational Accidents and Diseases

Conflict of interest declaration: none

\section{OPENING FUMIGATED CONTAINERS - SIMULATION OF SPATIAL GAS DISTRIBUTION AFTER GAS RELEASE FROM A FUMIGATED CHAMBER}

\section{Gabriele Flingelli, Dagmar W. Klementz}

Julius Kühn-Institut (JKI), German Federal Research Centre for Cultivated Plants, Institute for Ecological Chemistry, Plant Analysis and Stored Product Protection

Dr. Dagmar W. Klementz — e-mail: Dagmar.Klementz@jki.bund.de

Background: Fumigated import containers may threaten people who open or enter, if they are not aware of potential dangers due to missing or wrong declaration. Staff aboard ship or at the container terminal, customs officials and soldiers during inspection of ships at sea as well, run at this potential risk. It has also been discussed, based on field trial data (RIVM report 609021041/2007) that there could be a risk due to leakage from containers during fumigation. There is only little information available for the dilution of fumigants from containers during their aeration. According to the report mentioned above, there are recommendations for safety distances up to 50 metres, depending on the type, volume and concentration of the fumigant released from the container. Assuming insufficient tightness of containers during fumigation, a safety distance of 20 metres was recommended to be kept in order to protect bystanders. Though, these aspects of fumigation in Germany are clearly regulated by 'Technical Rules for Hazardous Substances, Fumigations TRGS 512'.
Methods: The gas dilution was simulated in a room after opening a fumigated test chamber. The experiments presented here were carried out with sulphuryl fluoride at concentrations $2 \mathrm{~g} / \mathrm{m}^{3}$ and $10 \mathrm{~g} / \mathrm{m}^{3}$. In various scenarios, the gas concentration was measured over time at different measuring points in the room with a Gasmet ${ }^{\mathrm{TM}}$ FTIR-spectrometer. A switch between measuring points was used to record 6 measuring point at the same time. Wind was simulated with the forced ventilation installed in the laboratory.

Results: In particular, when opening a small hole of the chamber, the gas concentrations in the room followed similar to a limiting case of diffusion. After $24 \mathrm{~h}$, residual concentrations above the occupational exposure limit of $10 \mathrm{mg} / \mathrm{m}^{3}$ in the chamber were still detectable. Complete opening of the door with simulated wind led to an unexpected high concentration of sulphuryl fluoride in the 'windward' area beneath the chamber.

Conclusions: As a summary, the results show in a first approach that it is difficult to predict gas concentrations in the context of fumigating containers and airing them. The risk for bystander due to leakage could be minimized using hand-held sensors, provided that the nature of the gas is known. The FTIR-spectroscopic method seems to be suitable for field trials too. Further investigation is necessary.

Funding: This work was supported by the Julius Kühn-Institut(JKI), German Federal Research Centre for Cultivated Plants

Conflict of interest declaration: the authors declare that they have no conflict of interest

\section{WORKERS' ILLNESSES BY TOXIC CHEMICALS IN ELECTRONIC PLANTS}

\section{Jeong-ok Kong}

Supporters for Health and Rights of People in Semiconductor Industry; Korea Institute of Labour Safety and Health; Centre of OEM in St. Mary's Hospital of the Catholic University of Korea

Dr. Jeong-ok Kong — e-mail: anotherkong@gmail.com

Samsung Electronics is famous brand company with the biggest global market shares of memory chip, smartphone, TVs, and monitors. Its production is based mainly on China, Korea, and Southeast Asia.

About two hundred cases of suspected occupational diseases including death of more than seventy persons from Samsung Electronics and its affiliates have been recognized by SHARPS, civil society group in Korea, based on the voluntary report of workers or their family.

Most of the workers got cancers or other rare diseases in their age of 20's or 30's. A recent study on the 21 cases of leukaemia and non-Hodgkin lymphoma of those workers 
from a single factory of Samsung semiconductor showed the mean age of diagnosis was 28.5. A different epidemiologic study on eight semiconductor factories between 1998 and 2008 also showed increased SIR and SMR of haematopoietic cancers especially in female workers despite of many limitations on study design.

The suspected cause of these illnesses is exposure to chemicals and hazards such as ionized radiation in the manufacturing processes. They use lots of hazardous chemicals in the electronics industry, usually without proper protection of workers. Manufacturing of semiconductor or LCD panels are especially highly dangerous because of hundreds of chemicals and their by-products with possibility of creating more toxic by-products via interaction.

There are some clusters of cancers and other illnesses - especially the reproductive problems - in the semiconductor factory of Samsung. For example, nine out of eighteen workers from a single shift of a final process of wafer fabrication have been contracted to serious health problems including three cases of cancer, diseases in thyroid, ovary, and lung, and reproductive problems such as miscarriage, infertility, and congenital heart anomaly of the offspring.

These women worked there in 1990's when they were 18 to 25 years old. They worked in three shifts per day with only one single day-off per month. They cleaned the workstation and machines everyday with isopropyl alcohol and acetone. They were ordered to clean up 'all visible surfaces' with those chemicals whenever the production facilities should be restarted after being shut down or blackout. In addition, they were exposed to variety of chemicals used in the processes. But the workers were not given any information on hazard of those chemicals.

If workers have been exposed to toxic chemicals and contracted to cancers in such a big company as Samsung, what about other workers in smaller companies in the world?

The impact of toxic chemicals from electronics industry on health of workers and local communities can be explosive considering rapid growth of this industry, the characteristic of the workforce with high proportion of young female, and the intensive usage of chemicals without proper protection of workers. It is not a local problem but a global one because of globalized supply chain and market which can export the hazards as well as the products.

\section{ONSITE MEASUREMENTS OF FUMIGATED CONTAINERS: POSSIBILITIES AND PROBLEMS}

\section{Andreas Walte, Wolf Münchmeyer, Henrik Lund}

Airsense Analytics GmbH

Dr. Andreas Walte — e-mail: walte@airsense.com
Introduction: In our globalized era most international goods are transported by commercial ships. Most of the world trade of packed goods is transported in containers. Unfortunately also fumigants and toxic industrial chemicals are also transported with the containers. Portable, fast and easy to use detection systems have to be developed in order to protect workers from the toxic environment in the containers.

The following paper will present the results of a joint research project (OPTIMA) funded by the Federal Ministry of Education and Research from Germany. The main goal of OPTIMA was to improve analytical methods in the lab and also onsite at the container in order to detect fumigants and toxic chemical compounds inside. The project started in January 2011 with the partners Airsense Analytics GmbH in Schwerin, the Institute for Occupational and Maritime Medicine of the University of Hamburg (ZfAM), the Fraunhofer Institute for Intelligent Analysis and Information Systems (IAIS) in Sankt Augustin and ended in March 2013. ZfAM was responsible for the development of a laboratory reference method for the analysis of fumigants and toxic industrial compounds. Furthermore ZfAM performed measurements in the harbour of Hamburg and was also responsible for sampling of gas bags. IAIS is an expert for Neural Networks and was responsible for the development of data analysis methods based on Neural Networks. Airsense wanted to improve its portable analysis instrumentation based on a Gas Detector Array (GDA).

Motivation of the project: Former studies and the results of the present project show that fumigants and other toxic gases at relevant concentration are very often present in the air of the containers. In some containers even high concentrations of fumigants can be found. Many containers still do not have any warning labels or contain "new" fumigants not known before. More often the containers are full of toxic industrial chemicals (TICS) from the production process. This means that for protection of personnel fast screening detection systems are needed. Target compounds, such as well-known fumigants, but also probably more important non target compounds, such as toxic gases used in production, have to be monitored. The goal of the project was to improve instrumentation and methodology for onsite monitoring as well for the laboratory analysis.

Target and non-target compounds: A good orientation about target compounds and their relevant concentrations can be found in the German "Technical Rules for Hazardous Substances - TRGS 5121". Fumigants and TICs listed are bromomethane (methyl bromide), phosphine, formaldehyde, sulphuryl fluoride and hydrogen cyanide. Ammonia, carbon monoxide, chloropicrin, ethylene oxide, benzene, toluene, styrene xylene, chloromethane and carbon dioxide were recently added to the list of relevant compounds. Relevant 
concentrations are in the low ppm range. Some examples are bromomethane with a TRGS threshold value of $1 \mathrm{ppm}$ (old value $=0.5 \mathrm{ppm}$ ), phosphine with $0.1 \mathrm{ppm}$ (old value $0.01 \mathrm{ppm}$ ), formaldehyde with $0.3 \mathrm{ppm}$ (old value $0.1 \mathrm{ppm}$ ) and sulphuryl fluoride with $2 \mathrm{ppm}$ (old value $=1 \mathrm{ppm}$ ). The new compounds have threshold values which are identical and very similar to the workplace threshold limit values (former MAK values) in the range of $0.1 \mathrm{ppm}$ for chloropicrin to $100 \mathrm{ppm}$ for the xylenes, with the exception of benzene with a low TRGS threshold value of $0.06 \mathrm{ppm}$ (http://www. baua.de/en/Topics-from-A-to-Z/Hazardous-Substances/ /TRGS/TRGS-512_content.html).

The problem with target compounds is that when focusing only onto the listed compounds containers with very toxic compounds can be declared as non-harmful. From the chemical analysis of the air in containers it is known that for example 1,2-dichloroethane is very often found. The compound is missing in the list, it is very common and unfortunately also a carcinogenic compound. Also other compounds such as carbon disulphide, dichloromethane, methyl iodide and dibromomethane are not in the list. The ideal detector should therefore be selective and sensitive enough in order to identify all the target compounds in the list, but should also at the same time be a more general detector capable to detect other non-target compounds.

Sampling methods and onsite measurements: Over 600 containers were measured by the ZfAM at customs from the harbour of Hamburg. Measurements were performed onsite with a gas detector array instrument (GDA, Airsense) by sampling through the online probe. The probe is inserted into the container by pushing away the sealing of the door with the advantage that the door has not to be opened. After the measurements with the hand held instrument special sampling bags (1 litre, ALTEF bags from Restek) were filled with the air of the containers. The air bags were transported to the laboratory of the ZfAM in order to perform measurements with gas chromatography - mass spectrometry (GC-MS). For the GC-MS analysis only around a small amount of the air was used. The bags were afterwards sent to the laboratory of Airsense, where different fumigants and TICs were added in order to generate different atmospheres for consecutive measurements with the GDA. By this way more than 2000 measurements were performed with the GDA.

Instrumentation: The volatile and semi-volatile compounds from the sampling bags were adsorbed on a cooled trap at $\mathrm{T}=-10^{\circ} \mathrm{C}$ (adsorbent material U-T14H2S, based on graphitised carbon, silica gel and quartz wool). The flow rate was $5 \mathrm{~mL} / \mathrm{min}$ and the duration $1 \mathrm{~min}$. Injection into the GC-MS was performed after a thermal desorption step in helium at $\mathrm{T}=300^{\circ} \mathrm{C}$ (Unity Airserver coupled to a Unity 2 TD unit from Markes Ltd.). A capillary GC-column (HP-1MS, $30 \mathrm{~m}, 0.25 \mathrm{~mm}$ i.d., $1 \mu \mathrm{m}$ ) is used for the separation of the mixtures. The eluting compounds were analysed by a quadrupole mass spectrometer (Agilent MS 5975C). The detection of phosphine with the mass spectrometer is difficult because of its relative low mass (MW: 34 ) and of co-eluting compounds. Therefore a din switch was integrated in the $\mathrm{GC}$ and the peak with the retention time of phosphine is transferred into another GC-column designed for very volatile compounds (CP-PoraPLOT, $25 \mathrm{~m}, 0.32 \mathrm{~mm}$ i.d., 10 $\mu \mathrm{m})$. A flame photometric detector (FPD) is used for the sensitive detection of phosphine. With this set up each bag was analysed twice (with and without switching).

The handheld instrument (GDA2, version GDA-F, from Airsense Analytics) consist of a combination of ion mobility spectrometer (IMS), photo ionization detector (PID), electrochemical cell (EC) and two metal oxide sensors (MOS). Most of the target compounds, such as halogenated compounds and cyanides produce negative ions and can be detected by the IMS. Especially the spectra of the halogenated compounds very often show characteristic fragments allowing the general identification of for example chlorinated or brominated compounds. Other compounds such as phosphine or benzene do not show any spectra in the IMS which means that not all fumigants or TICs can be detected with the IMS. Therefore other detectors for example the combination of MOS and EC, respectively the PID are needed. The standard GDA-F system is a screening device which warns if fumigants or TICs are present in the air of a container. It does not identify the toxic compounds.

Results from the OPTIMA project: The project was performed in order to improve and validate the laboratory analysis and the portable instrument. With the help of special Neural Networks (Echo State Networks, ESN) from the IAIS institute, which can analyse time series of measured data, an identification and quantification of selected target and non-target compounds is possible. Training of the ESN was performed at the IAIS with an external PC using the measurements from the samples provided by the ZfAM and the measurements after the defined addition of fumigants and TICs at the laboratory of Airsense. The raw data was reduced and histograms were generated from the IMS data with 50 channels for positive ions, 50 channels for negative ions and the four other detectors. Each channel was used as an independent input for the Neural Network. The ESN-model was implemented into the GDA after training it with 600 internal knots and with a selection of target compounds (bromomethane with an alarm threshold of 1.5 ppm, phosphine with an alarm threshold of $0.1 \mathrm{ppm}$ and formaldehyde with an alarm threshold of $1.5 \mathrm{ppm}$ ). As a result a target compound can be identified and quantified. With the implementation of the Neural Network a better identification is possible, but it has to be mentioned that the disadvantage is the high amount of data required and therefore the time consuming train- 
ing. The sampling and analysis procedure of the GDA were also optimized with detection limits generally in the range of $50 \mathrm{ppb}$ to $5 \mathrm{ppm}$ (depending on the substance) and providing results in less than $10 \mathrm{~s}$.

The laboratory system was optimized and validated at the ZfAM. The thermal desorption CG-MS (TD-GC-MS) laboratory analysis method has a very high selectivity and sensitivity (low ppb range). Furthermore a HPLC-UV method was developed for the analysis of formaldehyde. More than 600 GC-MS measurements were analysed. Many fumigants were found, even bromomethane (which is banned in the EU), but no container with a relevant concentration of SO2F2 was found. Many containers were found containing volatile organic compounds such as terpenes (pinene) and with different TICs such as benzene, toluene, 1,2-dichloroethane, dichloromethane and carbon disulphide. Compared to the past a lower percentage of fumigants in relevant concentrations was found (about $2 \%$ ), but TICs still occurred very often with concentrations higher than occupational exposure limits (about 35\%). It was found that about $0.6 \%$ of the containers had concentrations higher than IDLH values (dangerous for life or health). For example a container was measured with $750 \mathrm{ppm}$ bromomethane (1500x higher than occupational threshold limit value), one with 1100 ppm phosphine (11 000x higher than occupational threshold limit value), one with $450 \mathrm{ppm}$ 1,2-dichloroethane (450x higher than occupational threshold limit value), one with 800 ppm benzene (800x higher than occupational threshold limit value) and one with > 100000 ppm toluene (2500× higher than occupational threshold limit value).

Acknowledgement: The OPTIMA project was funded by the German Federal Ministry of Education and Research. The authors would like to acknowledge the intensive and fruitful collaboration of Prof. Lygia Budnik, Dr. Svea Fahrenholtz from the Institute for Occupational and Maritime Medicine (ZfAM) of the University of Hamburg and Dr. Hans-Ulrich Kobialka from the Fraunhofer Institute for Intelligent Analysis and Information Systems (IAIS).

\section{OCCURRENCE AND LEVELS OF VOCS IN CONTAINERS ARRIVING IN SWEDEN, INCLUDING ASPECTS ON PERSONAL EXPOSURE, VENTILATION AND SAMPLING POSITION}

\section{Gunar Johanson, Urban Svedberg}

Work Environment Toxicology, Institute of Environmental Medicine, Karolinska Institutet Stockholm, Sweden Department of Occupational and Environmental Medicine, Sundsvall Hospital, Sundsvall, Sweden

Prof. Dr. Gunnar Johanson - e-mail: gunnar.Johanson@ki.se Ass. Prof. Dr. Urban Svedberg - e-mail: urban.svedberg@lvn.se
Transports in ocean freight containers are steadily increasing and more than 600 million container units (TEUs) are handled by ports annually. Residual levels of fumigants as well as solvents and other volatile organic compounds (VOCs) emanating from the goods constitute safety risks which may affect unprepared workers upon entering the container. There are two types of major risks, (1) acute intoxication and (2) chronic effects such as cancer. The latter may occur as a result of single as well as repeat exposures. This presentation includes the importance of sampling position when analysing container air, occurrence and levels of VOCs in import containers arriving in Sweden, personal exposure during stripping, and evaluation of preventive ventilation methods.

Sampling position: To facilitate air sampling via the closed container door, we developed a flat-edged, stainless steel probe. Initially we inserted the probe, as is usually done, at the bottom of the door. However, repeat measurements from the same position sometimes resulted in strikingly different concentrations (measured with a direct-reading photoionisation detector, PID). In an extended comparison, we found that sampling at the bottom of the door in 6 of 38 comparisons gave a readout that was less than half (with some readouts being as low as $1 \%$ ), of that obtained when sampling at the mid or top.

Occurrence and levels of VOCs: For more specific analyses, we used high-resolution FTIR spectroscopy. Overall, 46 different chemicals were detected by FTIR in 256 examined containers at seven ports and terminals. Among noteworthy finding were the fumigants carbonyl sulphide ( 2 containers, 0.1 and 15 ppm), ethylene oxide (1 container, $1.7 \mathrm{ppm}$ ) and phosgene (1 container, $3 \mathrm{ppm}$ ). Also established carcinogens were found at significant levels, including chloroethanol (1 container, 6 ppm), 1,2-dichloroethane ( 2 containers, 10 and $30 \mathrm{ppm}$ ) and formaldehyde (9 containers, 0.2-2 ppm). The most frequent gases and VOCs (more than $10 \%$ of the containers, with levels sometimes near or exceeding the OEL) were carbon monoxide, carbon dioxide, ammonia, alfa-pinene and toluene. Notably, ammonia is not detected by many commonly used instruments. Overall, 16 different chemicals (10\% of the containers) were found at levels above half the Swedish 8-h OEL. Five percent had formaldehyde levels above $0.3 \mathrm{ppm}$ and $10-20 \%$ had VOC levels above 20 ppm. The highest exceedance was seen for 1,2-dichloroethanol (30 times above the $\mathrm{OEL}$ ) in a shoe container. The most abundant VOC in the shoe containers was toluene.

We further meta-analysed 1302 measurements of air from unopened containers performed at a container terminal during May-August 2013. The instrument used was a direct-reading instrument with detectors for VOCs, formaldehyde, hydrogen cyanide, phosphine and carbon monoxide. Of these measurements, 85 (7\%) were above 
the alarm level (roughly corresponding to the 8-h occupational exposure limit). These containers had to be ventilated before stripping. A more close analysis of the data suggests that many were false alarms, probably due to remaining detector cross-reactivity even after correction.

Personal exposure during stripping: Personal exposure was assessed during stripping of import containers at two distribution warehouses. A variety of methods were used; added tracer gas (nitrous oxide, $\mathrm{N}_{2} \mathrm{O}$ ) and "natural" VOCs, work zone and breathing zone monitoring, sample bags and continuous sampling, FTIR, PID and adsorbent tubes. The concentrations in the breathing zone during stripping of naturally ventilated containers ranged between $1 \%$ and $7 \%$ of that measured in the unopened container $(n=6)$. Initial peak levels up to $70 \%$ were seen.

Preventive ventilation methods: Different preventive ventilation methods were evaluated with the $\mathrm{N}_{2} \mathrm{O}$ tracer gas method. Preliminary data suggest that natural ventilation (open doors) and blowing ventilation (open doors, fan blowing air towards goods) have virtually no impact on tracer gas levels in deep container air (12 m from the doors). In contrast, extraction ventilation (fan sucking air via a tube inserted all the way into the container and fresh air entering via the doors) results in rapid washout of the tracer gas. However, the concentration does not reach zero but remains at a few percent of the pre-ventilation level. This likely reflects ongoing emission from the goods, a reminder that ventilation must be recent and preferably ongoing during stripping. $A$ ventilated container that is closed to be stripped next day must be re-ventilated.

\section{Conclusions:}

1. Residual harmful levels of fumigants can be found in unmarked containers (but not common).

2. Highly variable content, no handheld instrument covers all chemicals emitted from the goods.

3. Volatiles around or above the OELs were found in $5-20 \%$ of the containers.

4. Workers' exposures were 1-7\% of arrival (pre-open) concentrations (using natural ventilation), initial peaks up to $70 \%$ were seen.

5. Repeated and prolonged exposure may constitute health risk to those working inside containers.

6. Tracer gas method useful for experimental studies of exposure.

7. Measure before opening container (middle or top - not bottom). If not, always ventilate, preferably with forced extraction ventilation.

8. Extraction ventilation of container seems superior to natural or blowing ventilation (preliminary data).

9. A joint petition from the transportation industry and scientific communities for the redesign of containers to facilitate sampling and ventilation should be initiated.

Founding: The studies were financed by AFA Insurance and Västernorrland County Council 